\title{
Time-dependent electricity pricing using variable announcement horizons
}

\author{
Philipp Artur Kienscherf1 ${ }^{1} 2^{*}$, John Collins ${ }^{3}$, Carlee Joe-Wong ${ }^{4}$, Wolfgang Ketter ${ }^{1,2,5}$ and Soumya Sen ${ }^{6}$
}

From The 9th DACH+ Conference on Energy Informatics

Sierre, Switzerland. 29-30 October 2020

\section{*Correspondence:}

philipp.kienscherf@wiso.uni-koeln.de ${ }^{1}$ Cologne Institute for Information Systems, University of Cologne, Cologne, Germany

${ }^{2}$ Institute of Energy Economics at the University of Cologne, Cologne, Germany

Full list of author information is available at the end of the article

\begin{abstract}
In the battle against climate change, electrification plays an increasingly large role in our society. The growing use of electricity networks requires advanced coordination mechanisms to avoid the tragedy of the commons. In this paper, we explore the effects of optimum time-dependent pricing (TDP) on supplier surplus within electricity markets, using a parameterized optimization model. Varying not only the prices themselves, but also their announcement horizon, we show how the suppliers' optimal decision depends on risk aversion, forecasting quality, and end-user flexibility. The inclusion of procurement risk in our model shows that TDP can be beneficial for suppliers when they want to actively manage risk, even if expected profits are lower. At the same time, the shifting of end-user demand to low-cost times reduces the overall system cost, and potentially carbon emissions.
\end{abstract}

Keywords: Dynamic pricing, Smart grid, Risk management

\section{Introduction}

Electricity provision is a cornerstone of industrialized societies and a key contributor to their welfare and almost all economic activities. However, without proper coordination, overuse of the shared electricity network may occur, resulting in the tragedy of the commons (Gupta et al. 1997; Koolen et al. 2017). Whereas there is a solution to this challenge (granularly pricing the network within a smart market environment (Bichler et al. 2010)) this solution is often not feasible in real-world applications. Transaction costs, bounded rationality, and risk aversion are hindering the introduction of actual market environments. This is particularly true if small-scale end users would have to participate in them (Parag and Sovacool 2016; Yamamoto et al. 2008). In this work, we focus on an area in which this is particularly prevalent, the retail electricity sector.

In most liberalized electricity markets end-users subscribe to tariffs instead of participating directly in trading, as transaction costs prohibit trading activities for households or small-scale commercial electricity users (Ketter et al. 2018). Even today most tariffs

(c) The Author(s). 2020 Open Access This article is licensed under a Creative Commons Attribution 4.0 International License, which permits use, sharing, adaptation, distribution and reproduction in any medium or format, as long as you give appropriate credit to the original author(s) and the source, provide a link to the Creative Commons licence, and indicate if changes were made. The images or other third party material in this article are included in the article's Creative Commons licence, unless indicated otherwise in a credit line to the material. If material is not included in the article's Creative Commons licence and your intended use is not permitted by statutory regulation or exceeds the permitted use, you will need to obtain permission directly from the copyright holder. To view a copy of this licence, visit http://creativecommons.org/licenses/by/4.0/. 
are flat, meaning that users pay a uniform price per unit of energy, e.g., one kilowatthour, regardless of the time of consumption and the price of the upstream market (Fridgen et al. 2018). Suppliers absorb the price risk of the upstream market and the quantity risk of the consumption (cf. (Kaufmann et al. 2020)). Given the current smart meter roll-out in Europe and the increasing availability of home automation, we suppose that real-time pricing tariffs that are already available for larger customers might also become more available for residential consumers. Anyway, it is an interesting question for policy-makers what effect such tariffs might have on residential electricity consumption.

We reckon that end-users (or software agents that act on their behalf, respectively) are willing to adjust part of their consumption in exchange for monetary incentives, resulting in usable flexibility (Valogianni and Ketter 2016; Gottwalt et al. 2011; Ketter et al. 2013). We further assume that while there exists a general willingness to shift demand, varying prices induce transaction costs and risks for end-users (cf. (Ericson 2011)). Because of this, suppliers have to incentivize them to choose a tariff with varying prices, referred to as time-dependent pricing (TDP) for the remainder of this work. An offered discount in (expected) prices for the end-users captures this incentive. While longer pricing horizons are beneficial for end-users, as they (or their home automation system) can optimize their future demand accordingly, they expose the supplier to larger price risks on the procurement side of the electricity market. Shorter pricing horizons, however, reduce the end-users' ability to modify their demand to avoid high-cost times, reducing the impact of TDP. This user-supplier trade-off concerning the optimal pricing horizon is the focus and key contribution of this work. While traditionally many suppliers secured energy using long-term contracts, there is a significant shift towards the shorter-term markets against the backdrop of the diffusion of renewable energy sources. The described model anticipates such developments in wholesale energy markets (Koolen et al. 2017).

We consider a simplified and stylized electricity market model. We suppose that end-users buy their electricity from a supplier, who in turn purchases electricity from generators on a wholesale market. Note that numerous generators are typically present on electricity wholesale markets and that we do not incorporate idiosyncrasies of actual market designs in countries with liberalized electricity markets. Instead, we are using a stylized energy-only market on which the supplier can procure electricity. We assume that prices on the wholesale markets (the cost for the supplier) can be forecast (Ketter et al. 2009). Assuming that short-term predictions yield more accurate results than longer-term predictions, the price risk depends on the forecasting horizon (Ketter et al. 2012).

Our work embeds itself in the context of energy systems undergoing a substantial change as international agreements on climate change prevention accelerate the adoption of renewable energy resources (Ketter et al. 2018). Solar and wind energy as the most prevalent sources of renewable energy show an intermittent supply, meaning that they cannot be controlled at will but feed in energy whenever the weather conditions allow it. This leads to increased volatility on wholesale markets and the necessity to manage increased risk for suppliers (Boroumand et al. 2015). At the same time, demand must follow the supply curve closely as the power system has to be in balance at all times. Traditionally this was achieved by having supply follow the (exogenous) demand; however, this becomes increasingly difficult as the share of controllable resources such as nuclear and coal in the energy system decreases (Ketter et al. 2018). 
Changes to the demand-side reinforce the supply-side challenges faced by power systems. Accelerating penetration of electric vehicles, heat pumps, and general electrification increases the stress on the grid, in particular on distribution networks (Valogianni et al. 2018). While infrastructure expansion could, to a large degree, contain these challenges, this approach induces significant cost compared to the potentially cheaper option of leveraging flexibility within the power system (Kondziella and Bruckner 2016). Infrastructure capacity must support peak demand, as electricity networks have to sustain the highest occurring load flows. This is similar to other networked systems such as transportation or communication. As infrastructure sizing follows peak demand, peak shaving is a particularly desirable goal of flexibility utilization (Joe-Wong et al. 2012).

\section{Background and related literature}

This work lines up with interdisciplinary research manifesting itself in several streams of literature. We review the literature on energy informatics (Watson et al. 2010; Goebel et al. 2014) and smart market design (Bichler et al. 2010), as they provide a foundation for information systems (IS) research within the field of energy (economics). Further, we review the literature on demand response (DR) and demand flexibility (Gottwalt et al. 2011) as they describe the end-user flexibility we are seeking to leverage using a dynamic pricing approach. Note that we do not discuss research that specifically addresses demand-side management (DSM). Despite being widespread in the literature, as DSM typically focuses on centralized control approaches as opposed to the market-based incentives we describe. Due to the interdisciplinary character of recent energy research, seminal work on DSM and DR is available in IS literature as well as in engineering and economics. Last, we review the literature on dynamic pricing in general, as it is not only prevalent in electricity markets, but also in other fields energy research could draw from.

\section{Energy informatics and smart market design}

Beside the notion of smart grids that mostly refers to technical aspects of power system operation, energy informatics research explores the area of smart markets (Bichler et al. 2010) that can contribute to the economic side of next-generation power markets. The design of electricity markets, in particular with rapid changes within power systems, is a highly complex task, rendering it a wicked problem (Ketter et al. 2016a). Computational research, especially simulation of strategic behavior and policy, contributes to a better understanding of the necessities of future energy systems (Ketter et al. 2016b). Different methods to coordinate existing flexibility with economic approaches (Dauer et al. 2015) have been proposed, as well as approaches to economically value demand flexibility, e.g., using methods from mathematical finance (Fridgen et al. 2014). However, most work within this research stream does not focus on the retail side of the market and thus has a different perspective on end-user pricing than the approach we propose in this work.

\section{Demand response and demand-side management}

There is a close interconnection between research on DR, DSM, and dynamic pricing (Borenstein et al. 2002). In this subsection, we will review research regarding technical aspects, i.e., how information systems (IS) can create demand flexibility. In the next subsection, we will give an overview of dynamic pricing. On a residential level, most research focuses on two applications to achieve demand flexibility: Smart home technology 
(in conjunction with smart appliances), and electric vehicles (EVs). A reason for this is that residential cooling and heating units and EVs show the largest potential for flexibility (D'hulst et al. 2015). Research at the interface of IS and artificial intelligence (AI) shows how intelligent agents (IAs) within smart homes (Cook 2012) can schedule different appliances and EVs when these experience variable prices (Valogianni et al. 2020). Similar approaches exist as a decision support system for EV fleet operators (Eisel et al. 2015). IS cannot only leverage flexibility in the form of decision intelligence but also in the form of analytics to estimate the underlying demand elasticity of EV usage (Koroleva et al. 2014). The utility of IS in estimating flexibility within the energy system to support utilities has also been extensively researched (Fridgen et al. 2016; Schmidt and Busse 2013; Watson et al. 2013).

As this research shows, the availability of flexibility on a residential level can be substantial in the presence of suitable technology to unleash it. However, the IA approaches in this section consider households or fleet operators directly facing wholesale electricity prices, which is (at best) true for very large consumers. Therefore we contribute by including the supplier layer between end-users and the electricity market. We are not aware of demand flexibility literature that models the risk absorption by the intermediary the way we propose.

\section{Dynamic pricing}

Dynamic pricing is an important direction of IS research, as electronic markets (Bichler et al. 2001) enable both variable pricing and price discrimination through the use of IS. Research shows how dynamic pricing of electric vehicle (EV) charging can help to adjust the demand profile to a preferred shape (Valogianni et al. 2018) and how it can manage demand loads in smart grids (Joe-Wong et al. 2012). A more general view on dynamic pricing schemes by Borenstein et al. advocates a wider use of continually adjusted prices, especially for larger customers (Borenstein et al. 2002). Given the time of its writing in the early 2000s, it could hardly have foreseen the extent of the recent and ongoing developments in the area of home automation and, consequently, reduced transaction costs for smaller customers facing dynamic tariffs. Beyond short-term effects, dynamic prices may also reshape customer behavior in the long run (Borenstein 2005).

Beyond research in the electricity sector, this work also relates to the broader literature on the economics of data pricing in broadband networks. Dynamic pricing for data and communication usage has been investigated since the 1990s. Sen et. al. provide a detailed survey of various time-independent and dynamic pricing schemes in the existing literature (Sen et al. 2013; 2015). As early as 2001, dynamic pricing experiments for voice calls showed that static prices encouraged users to shift their calls from peak to off-peak times (Shih et al. 2001), although real-time pricing was not effective due to users' uncertainty in the future prices. A series of field experiments in operational networks has demonstrated the benefits of time-dependent pricing for mobile data (Ha et al. 2012; Sen et al. 2019). Subsequent work has investigated various optimizations of such pricing schemes and particularly the benefits of TDP compared to fixed-rate pricing (Zhang et al. 2014; Chang et al. 2015; Joe-Wong et al. 2011).

Dynamic pricing for data networks differs from that of energy markets in several ways. First, energy providers have a very different supply-side model because they procure energy from different sources (e.g., coal, water, nuclear) that have different production 
costs and availability constraints for the resource. Second, the reviewed data network pricing literature does not model the risk absorption by an intermediary because the network operators themselves typically own bandwidth licenses. Thirdly, prior works in data networks have focused on the effect of dynamic pricing on end-user behavior, rather than studying the question of selecting the right pricing horizon, which is the focus of this work.

Dynamic pricing has also been proposed for cloud markets, where Amazon EC2's spot instances are perhaps the most popular form of dynamic pricing: they essentially offer real-time auctions for computing resources (Zheng et al. 2015). Like data and electricity users, cloud users' demands for resources can vary over time, and mechanisms like virtual pricing attempt to incentivize users to spread this demand to avoid congestion (Jiang et al. 2019). However, most dynamic pricing schemes for cloud computing consider real-time pricing, with prices not announced in advance (Xu and Li 2013). Since much cloud usage is machine-driven to some degree (typically, cloud workloads do not require human intervention while they are running), it is easier for users to automatically adjust their cloud usage to real-time pricing than it would be for data or electricity usage. Pricing horizons have not been considered in cloud markets.

Despite the vast body of literature on DR and dynamic pricing, the authors are not aware of any research that a) considers a variable announcement horizon for the dynamic prices, and b) incorporates risk into the model. The contribution hence is an adaptable modeling framework that can be bootstrapped with real-world data for specific application cases.

\section{Demand model}

We model end-users' electricity consumption in presence of tariff pricing. That means that end-users are not directly subject to wholesale prices. Instead, suppliers offer tariffs to them. As opposed to flat tariffs, time-dependent-pricing (TDP) tariffs show varying prices for different times, e.g., hours during one day. Suppliers are passing on the volatility of the wholesale market to the downstream retail market to set the right incentives for customer behavior. A novelty to the approach is that pricing horizons do not have a fixed length, e.g., 24 hours (day-ahead pricing). Instead, we explore different pricing horizons' effect on resulting prices and suppliers' profits. Table 1 gives an overview of notation.

$H$ time-slots of equal length constitute a pricing horizon. The supplier maintains a rolling pricing horizon of length $H$, i.e., after every time-slot, she announces a new price. The supplier optimizes the risk-adjusted profit for a specific period of consideration, e.g., one day. We denote it as $T$. Other periods of consideration are equally possible, suppliers could optimize profits for a month or a year.

End-users in the model have a known time-dependent baseline demand $x_{t, \text { base }}$ under flat pricing $p_{\text {flat }}$. If end-users have advanced metering infrastructure (AMI), the supplier can estimate the baseline demand from historical data, otherwise, she may use standard load profiles. Users might be able and willing to shift some demand from a time-slot to another. This shifting does not necessarily require actual interventions by the users. Much rather software agents such as home energy management systems (HEMSs) would act on their behalf. In the past, residential electricity consumption has mostly been assumed to be inelastic as the inconvenience of behavioral change outweighs potential savings for most conceivable pricing regimes. However, with the growing availability of technological flexibility, e.g., battery storage or electric vehicles, combined with the increasing 
Table 1 Notation

\begin{tabular}{ll}
\hline Symbol & Description \\
\hline$H$ & Horizon length, i.e., time between price announcement and corresponding period. \\
$p_{f l a t}$ & Constant price of a flat tariff. \\
$p_{t}$ & Price at time $t$. \\
$x_{t, \text { base }}$ & Baseline demand at time $t$. \\
$x_{t}$ & Actual demand at time $t$. \\
$T$ & Supplier's periods of consideration. \\
$w(d, s)$ & Waiting function. Denotes the share of demand shifted s periods when there is a relative \\
$C_{t}$ & price difference of $d$. \\
$C_{t}$ & Random procurement cost at time $t$. \\
$\delta$ & Unbiased estimator for $C_{t}$. \\
$\lambda$ & Discount parameter. Denotes the average price reduction that has to be offered for TDP \\
$\varphi_{1}$ & to be competitive. \\
$\varphi_{2}$ & Risk aversion parameter. \\
$\varphi$ & Forecasting quality coefficient. Dropped in augmented model. \\
$\Pi_{t}$ & Forecasting quality decay rate. \\
$z_{c}(\cdot)$ & Equals $\varphi_{2}$ in augmented model. \\
$z_{f l a t}(\cdot)$ & Supplier's revenue at time $t$. \\
\hline & Supplier's risk-adjusted profit. \\
& Supplier's risk-adjusted profit under flat pricing. \\
\end{tabular}

availability of HEMSs, it is conceivable that demand elasticity will grow. Given these technologies, the potential to shift demand can be substantial. Note, however, that we are not assuming that consumers at any point would shift all of their demand. Partial inflexibility of demand is within the scope of our model.

\section{Baseline demand}

$x_{t, \text { base }}$ denotes the baseline demand of a population of end-users for electricity at any given time $t=1,2, \ldots, T$. The baseline is the demand of the users at time $t$ under flat pricing $p_{\text {flat }}$. While $x_{t, \text { base }}$ would be a random variable with substantial variance for single users, it can be treated as a deterministic variable for a sufficiently large population of customers. As most tariffs for residential or small-scale industrial and commercial customers in the electricity sector still follow a flat pricing scheme, it can be precisely estimated based on historical data, e.g., through the use of standard load profiles for residential customers (Meier et al. 1999) or using statistical learning methods. For the remainder of the work, we will assume that a sufficiently large population of customers has subscribed to the proposed TDP tariff, and treat $x_{t, b a s e}$ deterministically. This is a reasonable assumption as suppliers in tariff markets typically serve a vast number customers.

\section{Demand shifting}

Users can shift demand through technological flexibility. This flexibility may be due to actual storage technology such as batteries, as well as abstract storage technologies such as electric vehicles or thermal storage. Previous work in the field of smart grids lays the foundation for the model of demand shifting (Joe-Wong et al. 2012). The model can easily be adapted to incorporate a larger group of heterogeneous users by aggregating the demand of individual users or user groups.

The waiting function $w(d, s)$ denotes the share of consumption the user population shifts by an amount of time $s$, given a relative amount of money saved $d$. Even with 100\% 
of payments saved, it does not necessarily have to equal 1 , as some share of the baseline demand might be inflexible. Thus, $w\left(\frac{p_{t}-p_{s}}{p_{\text {flat }}},|s-t|\right)$ denotes the shifted share of demand from time $t$ to time $s$, where $|s-t|$ is the amount of time between periods $s$ and $t$, and $\frac{p_{t}-p_{s}}{p_{\text {flat }}}$ is the amount of money saved, relative to the known flat pricing scheme from before ( $p_{\text {flat }}$ serves as a baseline for shifting decisions). Note that this shifting can be bidirectional; users can shift their normal electricity usage to a later time, or they can use more electricity at the current time and less at a later time. Again, the model can be extended to a heterogeneous group of users by defining different waiting functions, or different parameters for individual users or user groups. Users are less likely to shift their usage from a time-slot to another as more time elapses between the two. We can mathematically capture this behavior by imposing $\frac{\partial w(d, s)}{\partial s}<0$; we also impose $\frac{\partial w(d, s)}{\partial d}>0$, since users would shift more usage if they can save more money by doing so. To incorporate these requirements, we choose

$$
w(d, s)=\frac{\max (d, 0)}{C_{w}(\beta)(s+1)^{\beta}},
$$

where $\beta>0$ parameterizes users' willingness to shift. A large $\beta$, for instance, would indicate that the users' probability of shifting decays rapidly as $s$ increases, indicating impatience. Here $C_{w}(\beta)$ is a parameter-specific normalization constant. Note that the waiting functions may also be time-dependent without changing the basic structure of the model. If the end-user price has significant fixed components (such as grid fees), the relative savings $\frac{p_{t}-p_{s}}{p_{\text {flat }}}$ will be substantially smaller than under more flexible pricing schemes. As the resulting lower amount of shifting can also be modeled with $C_{w}(\beta)$. For brevity, we are assuming a fully flexible end-user price.

\section{Pricing horizon}

The supplier maintains a window of $H$ future prices by posting one new price after each time-slot; we denote this a continuous pricing horizon. Figure 1 shows an explanatory case with $H=8$. The end-user makes a demand decision at $t=11$. Cells colored light blue are time-slots to which or from which users can shift energy demand, cells colored light red are time-slots to which or from which they could have shifted. Besides the continuous pricing horizon, there are other possibilities for variable price announcements, e.g., blocks of fixed length (simultaneous announcement of all prices for a certain time frame). However, we do not model such pricing schemes, as we assume the case of a rolling window to be the most realistic and most applicable.

Since the provider announces prices so that she maintains a continuous price horizon of $H$ time-slots, users can always shift their demand to the full extent of $H$. We find the end-user demand at time $t$ is

\begin{tabular}{l|llllllll|lll|lllll|llllllll}
\hline$t$ & 1 & 2 & 3 & 4 & 5 & 6 & 7 & 8 & 9 & 10 & 11 & 12 & 13 & 14 & 15 & 16 & 17 & 18 & 19 & 20 & 21 & 22 & 23 & 24
\end{tabular}

Fig. 1 Continuous Pricing Horizon 


$$
\begin{aligned}
x_{t}=x_{t, \text { base }} & -\sum_{s \neq t, s=t-H+1}^{t+H-1} x_{t, b a s e} w\left(\frac{p_{t}-p_{s}}{p_{\text {flat }}},|s-t|\right) \\
& +\sum_{s \neq t, s=t-H+1}^{t+H-1} x_{s, \text { base }} w\left(\frac{p_{s}-p_{t}}{p_{\text {flat }}},|t-s|\right) .
\end{aligned}
$$

Note that shifting from or to periods outside the period of consideration is possible, i.e., even when we are maximizing daily profits, we have to account for the fact that shifting can occur across days given sufficiently large pricing horizons. We ignore the potential start and end effects, as we can safely assume that tariff contracts persist substantially longer than both the periods and horizons we explore.

\section{Objective}

The supplier's objective is to find the prices $p_{t}$ and time horizon $H$ that optimize the (riskadjusted) profit in the period of consideration, e.g., one day. For a continuous pricing horizon, the profit $\Pi_{c}$ for the period of consideration is

$$
\Pi_{c}=\sum_{t=1}^{T} \Pi_{t}=\sum_{t=1}^{T}\left(p_{t} x_{t}-C_{t} x_{t}\right),
$$

where $C_{t}$ is a random variable that represents the per-unit cost at time $t$. It could represent the supplier's production or her purchases on the wholesale market. Even if $C_{t}$ denotes the cost of the supplier's production, it is a random variable, as generation quantity (for variable renewable energy) and operational disruptions can occur randomly, resulting in the necessity to procure electricity on the wholesale market. Note that $T=24$ in this work, however, other periods of consideration are equally possible. Since we choose a short period of consideration, we do not discount future profits.

Under monopoly assumption, the supplier could charge infinitely high prices as the short-term price elasticity of consumers is zero; users might shift their demand, but do not reduce their total demand in the short run. However, the supplier cannot charge prices that will increase total costs for the end-users, as suppliers in electricity (and other liberalized) markets face competition. We assume that users would only subscribe to TDP if their daily cost would not increase (even without shifting). Under this assumption, subscribing to TDP is a no-regret measure for users. Additionally, suppliers might have to offer a horizon-specific discount to incentivize users to subscribe to TDP. As TDP increases inconvenience and transaction costs, this discount is positive and decreasing in $H$.

$$
\sum_{t=1}^{T}\left(p_{t} x_{t, \text { base }}\right) \leq\left(\sum_{t=1}^{T}\left(p_{\text {flat }} x_{t, b a s e}\right)\right)\left(1-\frac{\delta}{H}\right) .
$$

We assume a mean-variance (aka $\mu-\sigma$ ) utility function of the supplier (cf. (Oum et al. 2006)). While such a utility function is not the only option to model risk aversion, it is a standard choice. With a deterministic demand pattern, the distribution of profits only depends on the distribution of the cost. The supplier forecasts cost up to a normally distributed error term, the profits are therefore also distributed normally; subtracting a risk term from the expected profits captures risk aversion. $\lambda$ is the coefficient of risk aversion. The objective of the supplier is then to maximize risk-adjusted profits 


$$
\max _{p_{1}, \ldots, p_{T}, H} z_{c}\left(p_{1}, \ldots, p_{T}, H\right) \equiv \mathbf{E}\left[\Pi_{c}\right]-\frac{\lambda}{2} \operatorname{Var}\left[\Pi_{c}\right]
$$

The user population's baseline demand is deterministic, $\operatorname{Var}\left[x_{t, b a s e}\right]=0$. Cost is predicted by an unbiased estimator $c_{t}$, i.e., $\operatorname{Var}\left[C_{t}\right]=\operatorname{Var}\left[\hat{c}_{t}+\epsilon_{t}\right]=\operatorname{Var}\left[\epsilon_{t}\right]$, where $\epsilon_{t}$ is the randomly distributed error term of the prediction at time $t$. The error terms are independently distributed between time-slots, therefore, $\operatorname{Cov}\left[\Pi_{t}, \Pi_{s}\right]=x_{s} x_{t} \operatorname{Cov}\left[C_{t}, C_{s}\right]=$ $x_{s} x_{t} \operatorname{Cov}\left[\epsilon_{t}, \epsilon_{s}\right]=0 \quad \forall t \neq s$. With this, we get

$$
\begin{aligned}
z_{c}(\cdot) & =\mathbf{E}\left[\sum_{t=1}^{T} \Pi_{t}\right]-\frac{\lambda}{2} \operatorname{Var}\left[\sum_{t=1}^{T} \Pi_{t}\right] \\
& =\sum_{t=1}^{T}\left(\mathbf{E}\left[\Pi_{t}\right]-\frac{\lambda}{2} x_{t}^{2} \operatorname{Var}\left[C_{t}\right]\right) \\
& =\sum_{t=1}^{T}\left(\left(p_{t}-c_{t}\right) x_{t}-\frac{\lambda}{2} x_{t}^{2} \operatorname{Var}\left[\epsilon_{t}\right]\right) .
\end{aligned}
$$

$\operatorname{Var}\left[\epsilon_{t}\right]$, the variance of the cost forecasting error term at time $t$, equals the mean square error of the prediction. The functional form of $\operatorname{Var}\left[\epsilon_{t}\right]$ depends highly on the used forecasting algorithm, as algorithms are performing best for different forecasting horizons (Aggarwal et al. 2009). We model $\operatorname{Var}\left[\epsilon_{t}\right]$ based on three assumptions. First, we assume that the supplier's forecasting error will be smaller for shorter forecasting horizons, as more relevant information for the price formation (e.g., power plant availability, weather) is available shortly before market clearing. Second, we assume the forecasting error converges to a final value for very long forecasting horizons. In particular, we suppose that it does not grow infinitely large. This is reasonable as even without precise short-term information there is a prior on cost distribution. Both these characteristics correspond to forecasting with autoregressive models (cf. (Hamilton 1994, Chapter 4)). Third, we assume that the forecasting error is proportional to the squared expected cost, i.e., there is a constant coefficient of variation. This is the strongest assumption, especially as it implies zero variance for an expected cost of zero. However, such a functional relationship between the error term and the expected value seems particularly reasonable for the electricity sector. As there is a convex supply curve, variance due to both supply and demand variation is bigger for higher price levels. Note, however, that other functional forms of $\operatorname{Var}\left[\epsilon_{t}\right]$ can easily be incorporated in our model. Under the given assumptions we can model $\operatorname{Var}\left[\epsilon_{t}\right]$ by

$$
\operatorname{Var}\left[\epsilon_{t}\right]=\varphi_{1}\left(1-\varphi_{2}^{-H}\right) c_{t}^{2}, \quad 0<\varphi_{1}, \quad 1<\varphi_{2}
$$

where $\varphi_{1}$ and $\varphi_{2}$ are forecasting parametrs. A higher value for $\varphi_{1}$ indicates a generally higher error term variance, whereas a higher value for $\varphi_{2}$ indicates faster convergence to the residual error variance of an infinitely long forecasting horizon; it denotes the myopia of the forecast. Strictly speaking, $\frac{\ln (2)}{\ln \left(\varphi_{2}\right)}$ is the half-life of the error variance reduction through forecasting. Note that $\varphi_{1}$ is multiplied with $\lambda$ in (8), rendering a distinction between them redundant. Therefore, $\varphi_{1} \equiv 1$ for the remainder of this paper. Note that adjustment of $\lambda$ in the simulations accounts for the dropped $\varphi_{1}$. For brevity, we define $\varphi_{2} \equiv \varphi$. It follows 


$$
z_{c}(\cdot)=\sum_{t=1}^{T}(\underbrace{\left(p_{t}-c_{t}\right) x_{t}}_{\text {Gross Profit }}-\underbrace{\frac{\lambda}{2} x_{t}^{2}\left(1-\varphi^{-H}\right) c_{t}^{2}}_{\text {Risk }}) .
$$

The intuition behind the non-discriminability of $\lambda$ and $\varphi_{1}$ is straightforward: given a better forecasting quality, the supplier's constant coefficient of risk aversion has to be higher to observe the same optimal decision.

Since we admit that suppliers can both increase and decrease prices compared to flat pricing, suppliers will exhaust their opportunity to increase prices to a degree where they are just competitive. However, we are restricting prices to $0 \leq p_{t} \leq 2 p_{\text {flat }} \forall t$ to be able to calculate $C_{w}$. Note that this restriction is never binding in our simulations. Under these assumptions, constraint (4) binds so that the maximization of (10) resembles a cost minimization problem.

The previously used concept of risk-adjustment is ill-defined for flat pricing, as there is no specific decision horizon. To compare the results of TDP and flat pricing, we adjust gross profits under flat pricing with a risk term corresponding to an infinitely long forecasting horizon, assuming that the supplier sets the flat pricing scheme well in advance of the period of consideration.

$$
z_{\text {flat }}(\cdot)=\sum_{t=1}^{T}(\underbrace{\left(p_{\text {flat }}-c_{t}\right) x_{t, \text { base }}}_{\text {Gross Profit }}-\underbrace{\frac{\lambda}{2} x_{t, \text { base }}^{2} c_{t}^{2}}_{\text {Risk }})
$$

Note that $z_{\text {flat }}$ is not a function of the pricing horizons, as is intuitive. For non-zero usage and cost, the risk under flat pricing is strictly higher than under TDP, because the supplier has less freedom to manage its risk. Comparing (10) and (11) one recovers the supplier's three-part gain from offering a TDP tariff.

$$
\begin{aligned}
\Delta z & =z_{c}(\cdot)-z_{\text {flat }}(\cdot) \\
& =\underbrace{\sum_{t=1}^{T}\left(p_{t} x_{t}-p_{\text {flat }} x_{t, \text { base }}\right)}_{\geq 0, \text { risk avoided }}+\underbrace{\sum_{t=1}^{T}\left(c_{t}\left(x_{t, \text { base }}-x_{t}\right)\right)} \\
& +\underbrace{\sum_{t=1}^{T}\left(\frac{\lambda}{2} c_{t}^{2}\left(x_{t, \text { base }}^{2}-x_{t}^{2}\left(1-\varphi^{-H}\right)\right)\right)}_{\geq 0, \text { procurement savings }}
\end{aligned}
$$

The magnitude of the terms determines the profitability of TDP for the supplier.

\section{Simulations}

The results of the optimal pricing horizon and horizon-specific prices significantly depends on the choice of parameters. Because of this, we will vary the impatience parameter $\beta$, the discount parameter $\delta$, the risk aversion (and forecast quality) parameter $\lambda$, and the myopia parameter $\varphi$ over a wide range. $C_{w}(\beta)$ is calculated based on $\beta$ and $H$ to ensure that there can never be more energy shifted from a time-slot than consumed in the baseline case (i.e., we do not allow negative net demand).

We consider pricing horizons of length $H \in \mathfrak{H}, \mathfrak{H}=\{2,3,4,6,8,12,24\}$ within one day, i.e., $T=24$. To compare the effects of different pricing horizons, we optimize 


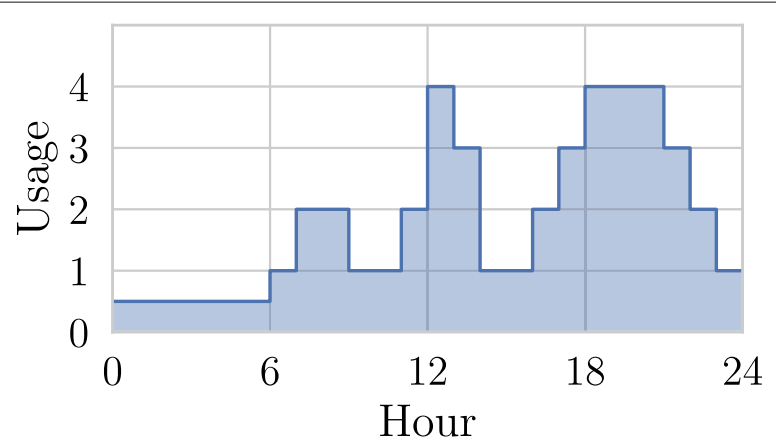

Fig. 2 Standard load profile

the risk-adjusted profit concerning an exogenous pricing horizon, i.e., using an exhaustive search for the optimal $H$. As the pricing horizon can only take (specific) integer values whereas the prices are continuous, we have a mixed-integer (MI) problem. Furthermore, the shifting function is non-linear. Therefore, we have a mixed-integer non-linear program (MINLP). Using exhaustive search concerning the pricing horizon leaves $|\mathfrak{H}|$ non-linear problems (NLPs) per parameter combination. Solving several of NLPs instead of a mixed-integer non-linear program (MINLP) has the additional advantage of superior solver availability.

The baseline demand rests upon the standard load profile for residential electricity customers in Germany (Meier et al. 1999). Flat pricing is $p_{\text {flat }}=0.25$ to create a comprehensible reference system. Note that we refrain from using units in this work and that we are abstracting from all fees and surcharges that are priced into existing retail electricity tariffs, as they are not decision variables of the supplier. Expected costs equal stylized average prices of the German intraday electricity market. Figures 2 and 3 show both the standard load profile and the stylized price curve, respectively. Note that both capture important real-world aspects of the German energy system. The model itself does not depend on that given structure.

Demand is low during night time. During the morning hours, there is a steep increase when people are cooking breakfast or showering using an electric water heater. Before noon, there is a period of low consumption again before cooking leads to a steep increase at noon. During the early afternoon, there is low usage again before a long period of high usage in the early evening hours, caused by multimedia consumption, cooking, and other activities. The stylized prices of the electricity wholesale market follow a similar

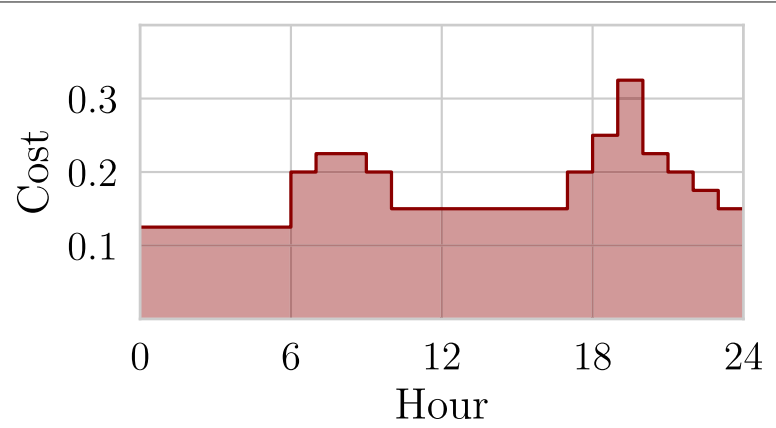

Fig. 3 Stylized cost 
trend, as flexible but expensive power plants have to serve demand peaks. The most significant deviation between consumption and cost trends is at noon, where demand is high but prices do not increase. The reason is that solar generation peaks at noon, coinciding with the demand peak. An increasing amount of solar generators in the energy system will further reduce midday electricity prices, even though it is a time of high demand.

The impatience parameter is $\beta \in\{0.5898,0.6355,2.8,3.0,4.0\}$ to allow for a wide range of potential user types. Note that for a high value of $\beta$ the probability of shifting demand by two or more time-slots is substantially smaller than shifting a single time-slot and is therefore neglectable, representing either a low ability or a low willingness to shift. The discount parameter between zero and 0.5, i.e., $\delta \in\{0,0.1,0.2,0.3,0.4,0.5\}$. While a discount parameter of zero denotes that shorter horizons cause no additional inconvenience, a discount factor of 0.5 denotes the case that a discount of $25 \%$ is necessary for end-users to consider TDP with a two-period horizon.

The risk aversion parameter is between 0.1 and 1 , i.e., $\lambda \in\{0.1,0.15,0.3,0.5,1\}$. This corresponds to a coefficient of risk aversion between 1 and 10 as seen in the literature on decision-making for portfolio investments in conjunction with a constant coefficient of variation (CV) of the root-mean-square deviation (RMSE) of approx. 0.3. A CV of the RMSE of 0.3 implies that the RSME accounts for $30 \%$ of the mean cost, or that the meansquare error (MSE) accounts for $10 \%$ of the squared mean costs, respectively. Hence, the values for the coefficient of risk aversion are scaled by 0.1. Note that the actual MSE of electricity price forecasts depends significantly on the used forecasting algorithm, forecast horizon, market, product, etc. Still, we are confident that the variation of $\lambda$ within one order of magnitude is sufficient to describe the effect of risk aversion given imperfect forecasts.

The myopia parameter is to $\varphi \in\{1.01,1.02,1.05,1.1,1.5\}$. While a factor of 1.5 describes an error variance reduction of approximately $67 \%$ for a forecasting horizon of a single time-slot, and practically no error variance reduction for a forecasting horizon of 24 timeslots, a factor of 1.01 describes an almost linear error variance reduction from $99 \%$ to $21 \%$ for a forecasting horizon of one and 24 hours, respectively. The parameter variation combined with the exogenously determined pricing horizon $H$ results in a total number of 5250 simulation runs.

\section{Results and discussion}

Figure 4 shows the distribution of the optimal objective function values for TDP and the risk-adjusted profit for flat pricing (the black line designates the risk-adjusted profit for $\lambda=0.3$, the borders of the grey areas the other values for $\lambda$ ). Note the clipping at an objective function value of 0.0 , so that not all results are visible for a discount parameter of $\delta=0.5$ and flat pricing, respectively. The optimal objective function value greatly depends on the choice of parameters. While the greatest variance stems from the discount parameter $\delta$, the other parameters also significantly influence the outcome. When endusers do not expect a discount, i.e., $\delta=0$, the optimum is virtually the same for all pricing horizons but the longest. This is since for short or moderate pricing horizons, the reduced procurement cost and the increased risk are balanced. For a long pricing horizon, i.e. $H=$ 24 , the risk increase is so substantial that even the enhanced shifting cannot outweigh the discount. 


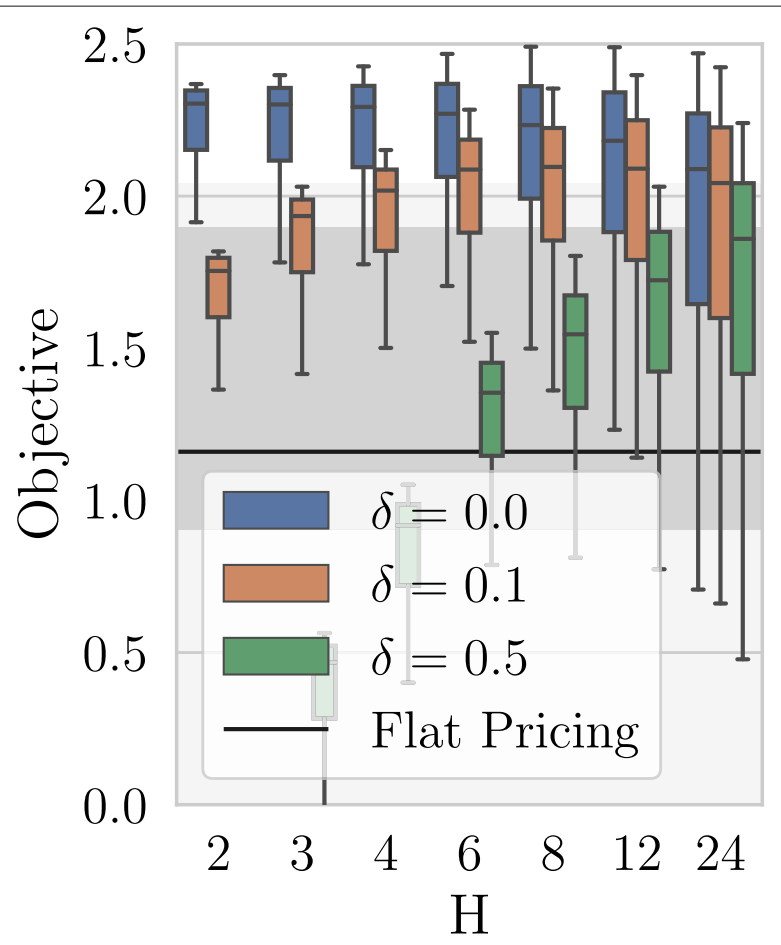

Fig. 4 Optimal objective function values subject to simultaneous parameter variation

Risk-adjusted profits under flat pricing are significantly smaller for most values of $\lambda$. Only with a large discount parameter $\delta$, TDP lacks competitiveness for shorter pricing horizons. The result, however, is different when looking at gross-profits, i.e., ignoring risk adjustments, in Fig. 5. Here, TDP is not competitive for short pricing horizons and barely competitive even for longer pricing horizons. The foregone profits due to the offered discount are so significant that the procurement cost decrease due to shifting is not substantial enough to outweigh its effect. Without a discount, the mean gross profits are higher for all pricing horizons, as the opportunity to modify prices increases the degrees of freedom for the supplier without any disadvantages. The comparison of TDP and flat pricing, as well as risk-adjusted and gross profits, shows how substantial the effect of risk management is for the optimal decision making of the supplier. Strikingly, if the supplier is risk-neutral, then TDP can only be competitive if the discount is near zero. If, however, the supplier is highly risk-averse, TDP can be preferable even if end-users expect large discounts, and expected profits are lower.

Figures 6 and 7 show the objective value and the optimal choice for $H$ when $\beta$ is 0.5898 (a high willingness to shift), and $\delta$ is 0.2 (a moderate discount factor). Figure 6 shows that longer pricing horizons attain higher objective function values (given a medium risk aversion of $\lambda=0.3$ ) as long as the myopia parameter $\varphi$ is low (farsighted forecasts are possible). This is since lower discounts are necessary and there is only a moderate risk adjustment. However, Fig. 7 shows that the optimal choice of $H$ varies for higher risk aversion parameters. Especially for myopic cost predictions, a shorter pricing horizon yields high utility under increased risk aversion. Note that $\varphi=1.5$ is an outlier, as forecasting risk is high for all forecasting horizons with a myopia parameter this high. 


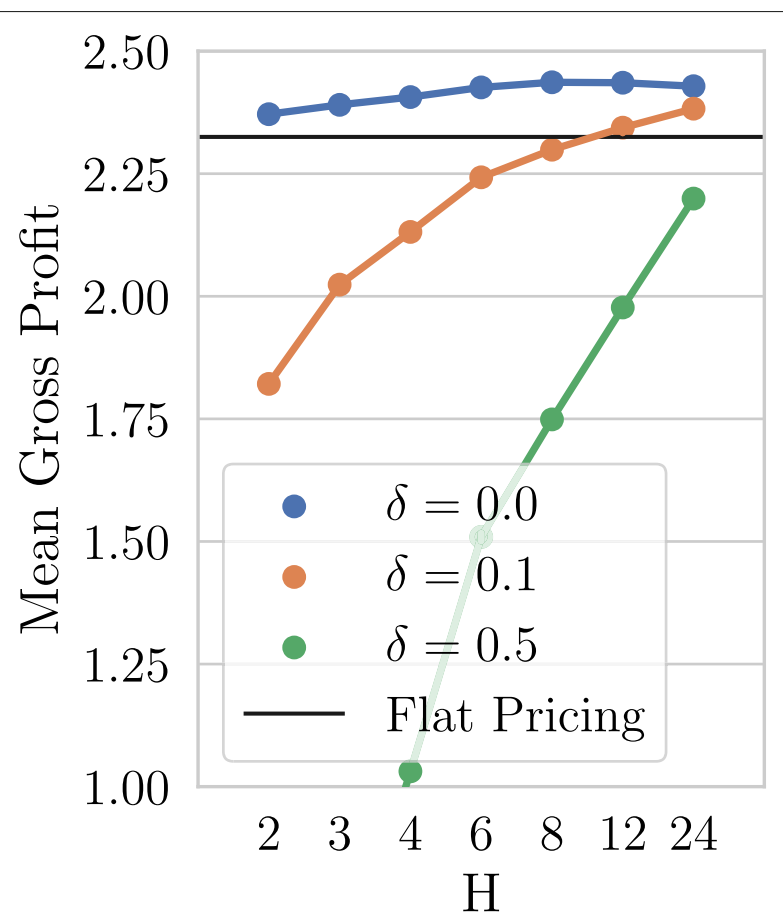

Fig. 5 Mean gross profit under TDP and flat pricing

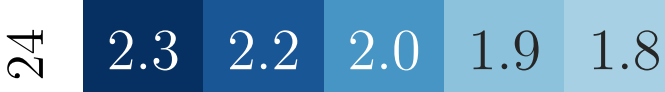

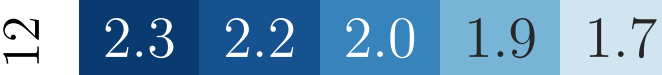

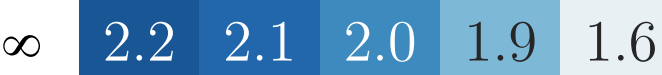

$$
\begin{aligned}
& \text { Ш } \\
& \begin{array}{llllll}
* & 1.9 & 1.8 & 1.8 & 1.7 & 1.3
\end{array}
\end{aligned}
$$

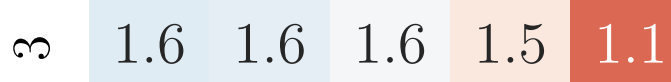

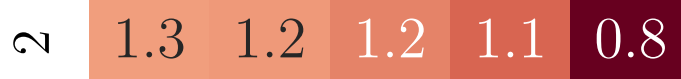

$$
\begin{aligned}
& \begin{array}{lllll}
1.01 & 1.02 & 1.05 & 1.1 & 1.5
\end{array} \\
& \varphi
\end{aligned}
$$

Fig. 6 Optimal objective function value for different pricing horizons $(\lambda=0.3)$ 


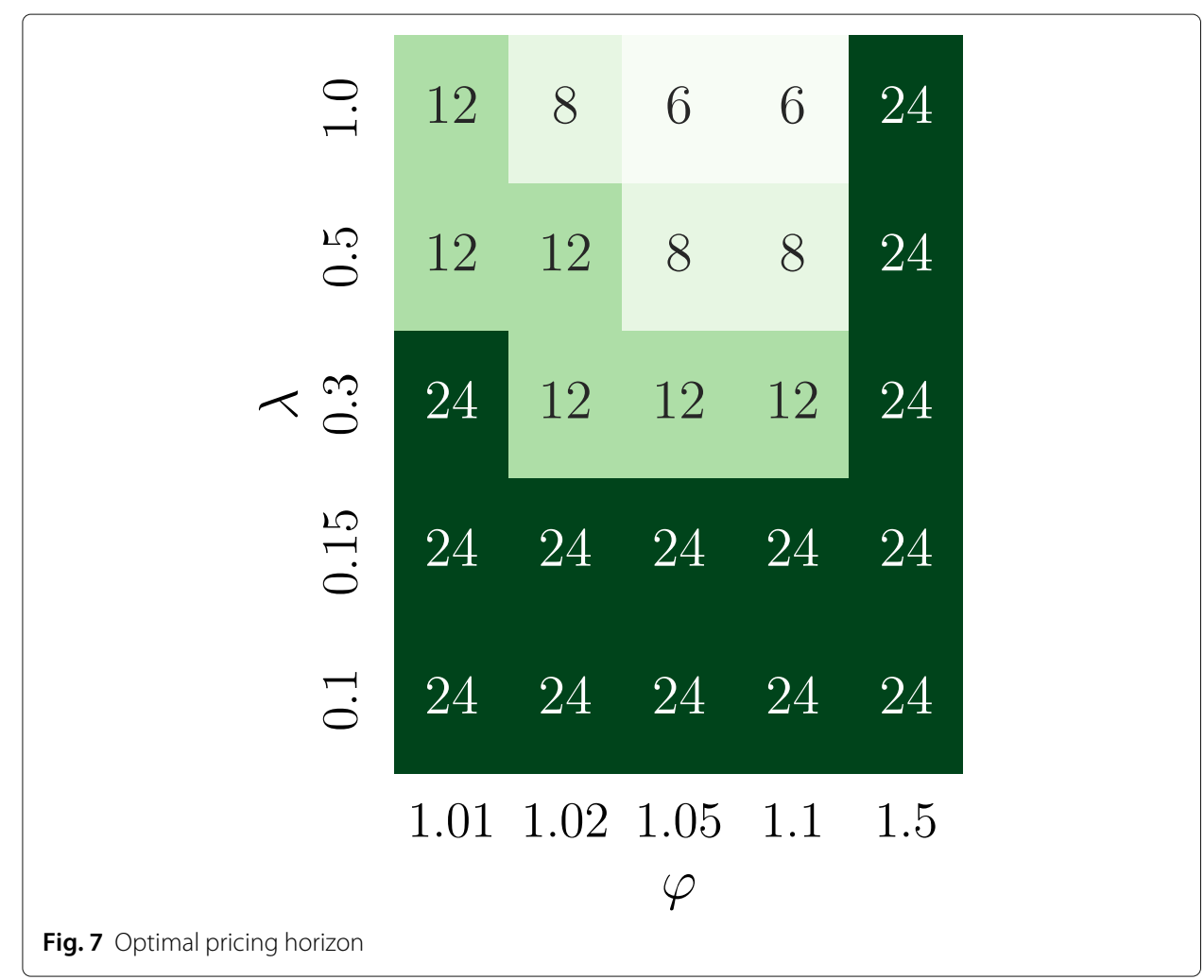

Figure 8 shows the difference in risk-adjusted profit for the optimal pricing horizon from Fig. 7 and flat pricing. The difference can be substantial, especially for significant risk aversion and low myopia. This seems reasonable as TDP gets particularly attractive for the supplier if she wants to actively manage her risk exposure and can do so using reliable forecasts. For insignificant risk aversion and high myopia, the advantage of TDP is still existing, even if shrinking considerably. Generally speaking, the advantage of offering TDP instead of flat pricing increases with the availability of reliable forecasts and risk aversion.

Figure 6 shows that, for a myopia parameter of $\varphi=1.05$ (and a risk aversion parameter of $\lambda=0.3$ ), the optimal objective value is comparable for pricing horizons between 6 and 24 hours (with $H=12$ yielding the highest results). To disentangle the different effects contributing to this result, Fig. 9 shows the pricing for these parameters 24-hour pricing horizon. We omit the other horizons as the optimal pricing is very similar across the different horizons. Clear peaks are visible around approx. 8-10 AM and 7-8 PM, i.e., high demand times with high procurement cost. Around noon end-user prices are low albeit there is an increased consumption; this is since procurement is cheap at midday. Price peaks at high-usage, high-cost times are more distinct for longer pricing horizons, as it is easier to make end-users shift their demand in this case. However, this increase leads to the necessity to slightly reduce prices at low-cost times to stay competitive.

The usage shifting of end-users through the time-dependent pricing is notable, as Fig. 10 shows. Note that, again, the figure only shows the 24-hour horizon for clarity. Shifting patterns are similar between different pricing horizons, but most pronounced for the 24-hour horizon. TDP primarily serves by incentivizing demand shifting away from 


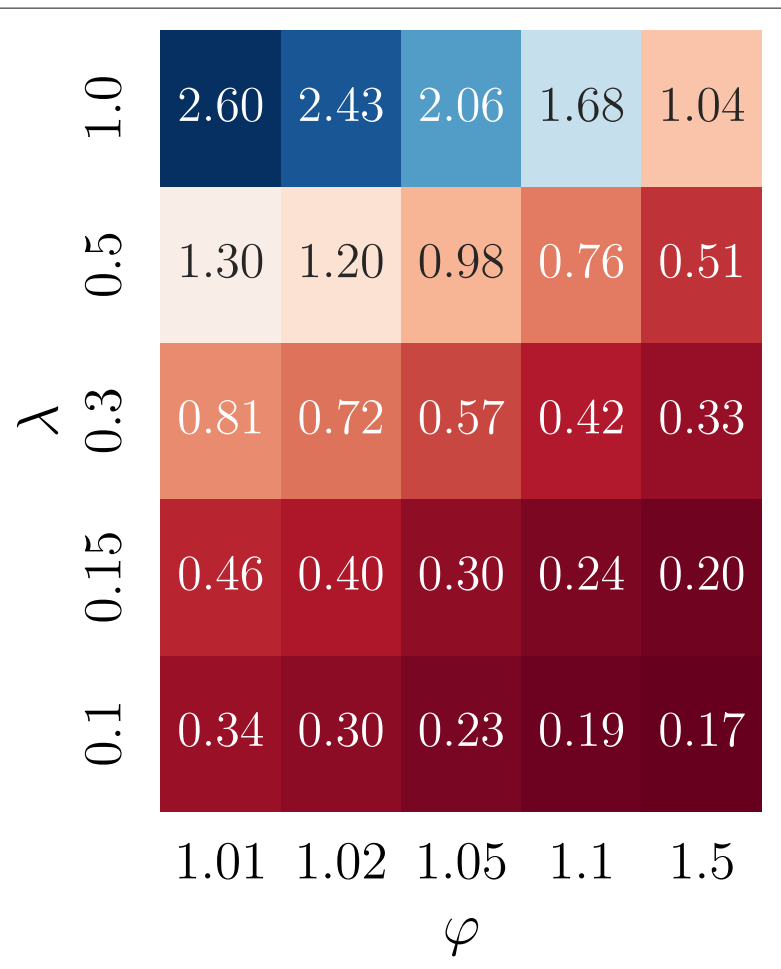

Fig. 8 Difference of objective function value for the optimal pricing horizon and flat pricing

the expensive evening hours. This is more successful for longer pricing horizons, as there are more alternative time-slots to which end-users can shift their consumption (since $\beta$ is small in this setting, the willingness to shift by even more than one hour is relatively high). For $H=24$, users shift more than one-third of the baseline demand at 7-8 PM to other time-slots, resulting in a significant procurement benefit for the supplier. Not only the procurement costs but also the absorbed risk is smaller if the supplier successfully incentivizes shifting from high-cost times, as the risk associated with demand at a specific timeslot increases quadratically with the expected demand and the expected cost (see (10)). The inclusion of risk as opposed to a purely deterministic model shows more distinct differences between cheap and expensive time-slots. Shifting directions are mostly equal for all pricing horizons, as the characteristics of load profile and cost throughout the day conclusively determine expensive and inexpensive times for the supplier.

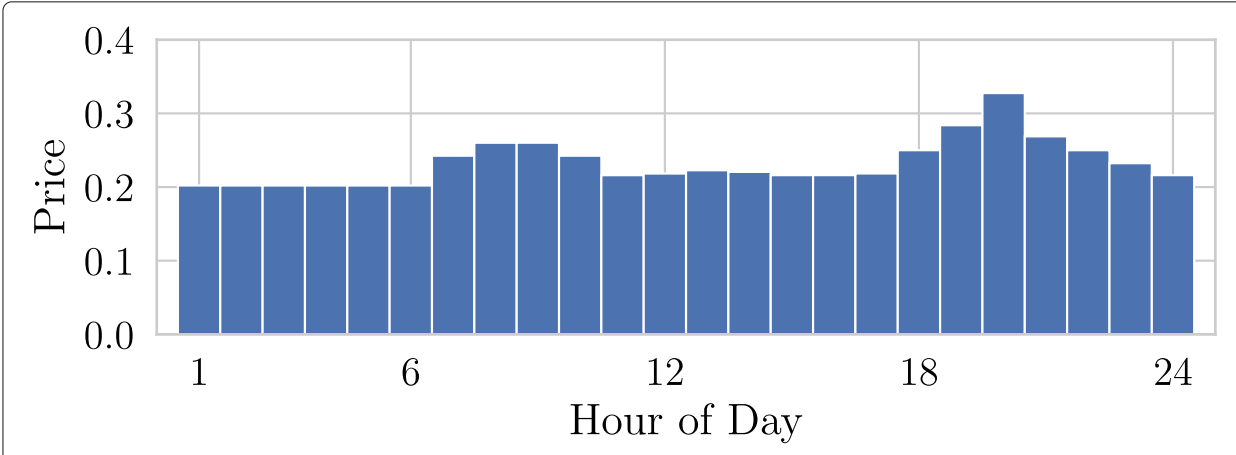

Fig. 9 Optimal pricing for a 24-hour pricing horizon 


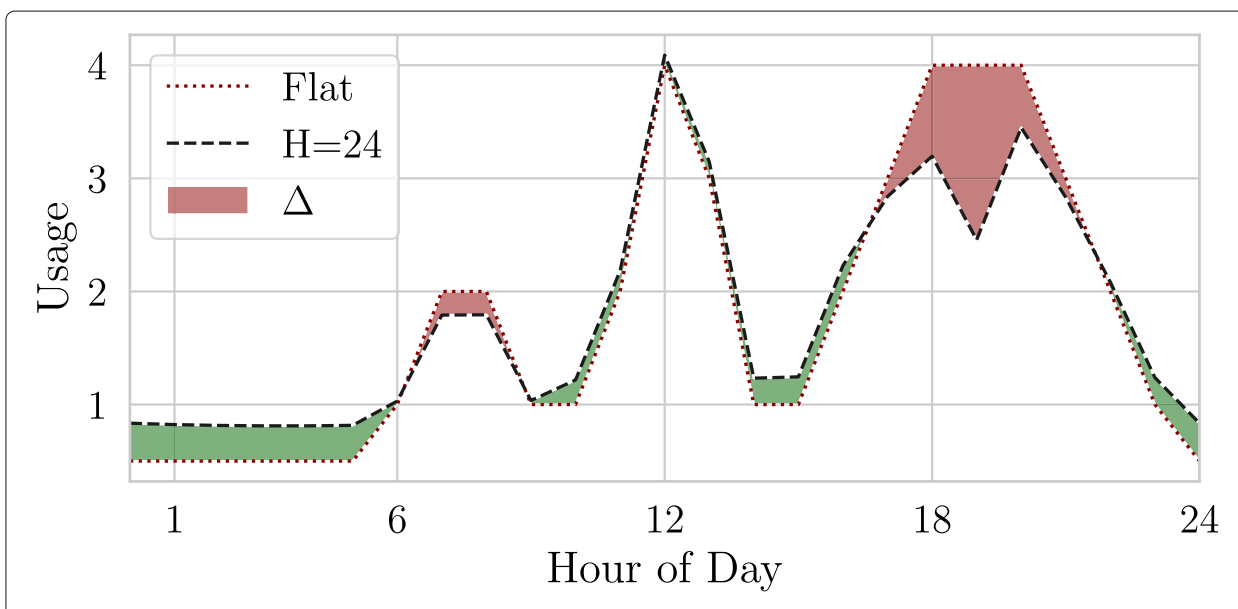

Fig. 10 Usage shifting under the optimally priced 24-hour horizon

Figure 11 shows the dependence of the optimal objective function values for the different input parameters. Each parameter is varied independently, meaning that all but the varied parameter take their most beneficial form, e.g., the risk aversion parameter is 0.1 during the variation of the other parameters. The discount parameter is the largest driver of variation in the optimal objective function value, followed by the myopia parameter. The effect of the risk aversion parameter is slightly lower, the effect of $\beta$ the smallest of the four.

All parameters but $\beta$ are direct results of the availability of information systems for the end-users or the supplier. Both the risk aversion parameter $\lambda$ (recall that $\lambda$ also includes a term of general forecast quality) and the forecast myopia $\varphi$ depend on the possibility to accurately predict wholesale prices as long in advance as possible. Prediction methods using artificial intelligence (AI) can contribute to the availability of such methods. The discount parameter $\delta$ reflects the inconvenience caused for an end-user by subscribing to short-term TDP. An automated HEMS, such as smart home technology, may reduce the
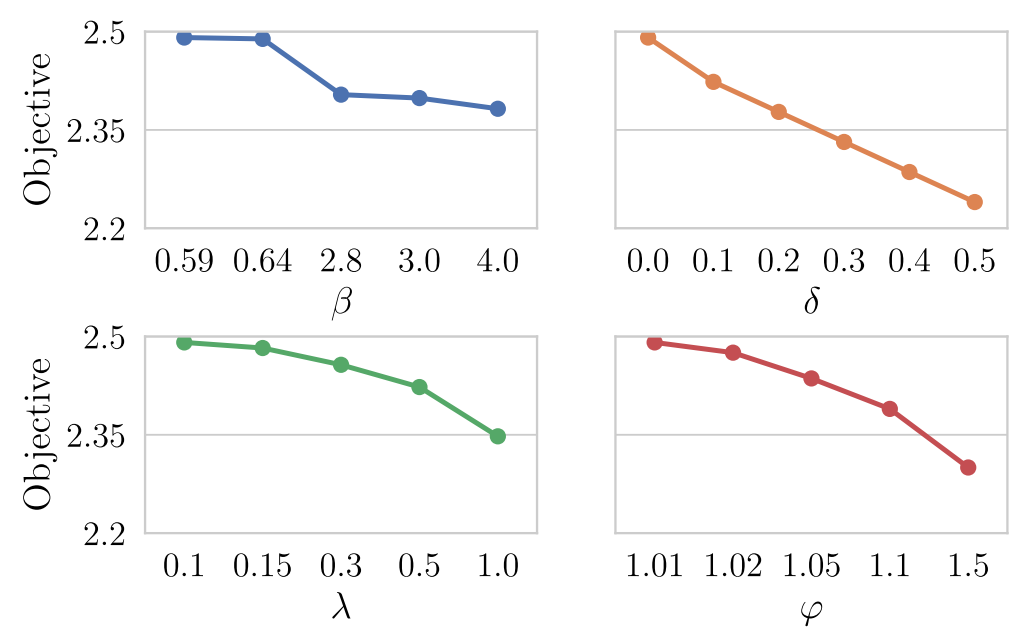

Fig. 11 Optimal objective function value under separate parameter variation 
perceived inconvenience. An intelligent agent as part of the $\mathrm{SH}$ can also predict prices not currently set and thus enable reasonable shifting beyond the horizon.

\section{Conclusions and future work}

We proposed a modeling framework to describe end-users' consumption shifting for electricity under TDP. There are different aspects of risk in the model, especially the supplier's risk aversion and the time-dependence of forecasting precision. These aspects significantly influence the optimal decision-making of suppliers in the context of network economics. They outline how state-of-the-art information systems reducing uncertainty on the supply-side and inconvenience on the demand-side can influence the supplier's optimal pricing horizon decisions.

We show that particularly in the presence of significant risk-aversion, TDP shows substantial advantages compared to flat pricing, as suppliers may reduce both the procurement cost itself and the corresponding risk. By actively taking suppliers' risk into account we were able to show that even if gross profits are lower under a TDP scheme, it can be beneficial for the supplier's utility to offer such a tariff. Because users only subscribe to TDP if it does not reduce their utility, we can show that the aggregated utility of both the supplier and users can be increased given the non-zero risk aversion, leading to an increased overall welfare.

Shifting only renders a significant advantage if the price dispersion is sufficiently large. Our results show that prices during costly evening hours are regularly $50 \%$ higher than during low-cost time. Being able to create such a price spread requires the possibility to almost fully pass on wholesale developments to the end-users. However, time-independent fees and surcharges largely drive current residential electricity prices. A policy implication of our work is therefore that by allowing for time-dependent fees, e.g., grid congestion fees, a welfare increase is attainable that contributes to both supplier and user rents. A worthwhile extension of the paper would be a non-zero long-term price elasticity to include behavioral change of end-users subject to TDP. In a dynamic setting with a changing baseline demand, new dimensions of complexity for the supplier arise. Additionally, demand uncertainty could be included.

Active modeling of competition between suppliers could be included in an extension of this work. Currently, we model competition ad hoc to incorporate the necessity to offer prices comparable to the status quo. However, if profit (or utility, respectively) increases are possible due to TDP, competitors presumably would also switch from flat pricing to TDP. Exploring the equilibria resulting from such competition is an ample direction for future research. Characteristics of existing markets could be modeled in more detail, especially the availability of financial derivatives to manage risks, e.g., futures and forwards. The decision space of how to procure on different markets and how to set prices accordingly then is significantly larger, and the necessity for a decision support system is all the more necessary.

The parameterization of the demand shifting (and the long-term price elasticity) could be validated using real-world data. We explored the space of potential willingness to pay by parameter variation. Instead, appliance-specific models are conceivable. A distinction between forward and backward shifting or non-proportional shifting might be interesting. Another aspect on the demand-side would be the introduction of a variable discount parameter. The necessary discount may depend on other factors than just the pricing 
horizon. For instance, it is conceivable that lower discounts are necessary when the price dispersion is low as opposed to highly variable prices.

Offering a portfolio of tariffs to leverage heterogeneity between end-users could be a highly interesting direction for further research. Typically, suppliers do not just offer one tariff but can build a portfolio of customers who self-select their ideal tariff. How different users would react to an offering of tariffs and how the resulting portfolio of end-users would look like are extremely important managerial questions for suppliers being active in tariff markets. Last, further research should scrutinize the presented model, in particular the defined waiting function and the discount magnitude, using a real-world pilot. Such a study was outside the scope of the presented work, however, it ultimately ought to be the goal to validate modeling choices in light of actual end-user behavior.

\section{About this supplement}

This article has been published as part of Energy Informatics Volume 3 Supplement 1, 2020: Proceedings of the 9th DACH+ Conference on Energy Informatics. The full contents of the supplement are available online at https://energyinformatics. springeropen.com/articles/supplements/volume-3-supplement-1.

\section{Authors' contributions}

All authors conceptualized the paper. CJW and SS provided the background on dynamic pricing in non-energy applications. WK and JC provided the background on dynamic pricing in energy applications. PAK wrote the first draft and implemented the simulations. All authors read and approved the final manuscript

\section{Funding}

Publication costs were covered by the DACH+ Energy Informatics Conference Organizers, supported by the Swiss Federal Office of Energy.

\section{Availability of data and materials}

Not applicable.

\section{Competing interests}

The authors declare that they have no competing interests.

\section{Author details}

${ }^{1}$ Cologne Institute for Information Systems, University of Cologne, Cologne, Germany. ${ }^{2}$ Institute of Energy Economics at the University of Cologne, Cologne, Germany. ${ }^{3}$ University of Minnesota, Minneapolis, USA. ${ }^{4}$ Carnegie Mellon University, Pittsburgh, USA. ${ }^{5}$ Rotterdam School of Management, Erasmus University, Rotterdam, Netherlands. ${ }^{6}$ Carlson School of Management, University of Minnesota, Minneapolis, USA.

Published: 28 October 2020

\section{References}

Aggarwal SK, Saini LM, Kumar A (2009) Electricity price forecasting in deregulated markets: A review and evaluation. Int J Electr Power Energy Syst 31 (1):13-22. https://doi.org/10.1016/j.jjepes.2008.09.003

Bichler M, Field S, Werthner H (2001) Introduction: theory and application of electronic market design. Electron Commer Res 1(3):215-220. https://doi.org/10.1023/A:1011512919970

Bichler M, Gupta A, Ketter W (2010) Research commentary -designing smart markets. Inf Syst Res 21(4):688-699. https://doi.org/10.1287/isre.1100.0316

Borenstein S (2005) The long-run efficiency of real-time electricity pricing. Energy J 26(3). https://doi.org/10.5547/ ISSN0195-6574-EJ-VOL26-NO3-5.BERTSEKAS

Borenstein S, Jaske M, Rosenfeld A (2002) Dynamic pricing, advanced metering and demand response in electricity markets. CSEM WP 105. University of California Energy Institute. https://www.haas.berkeley.edu/wp-content/ uploads/csemwp105.pdf

Boroumand RH, Goutte S, Porcher S, Porcher T (2015) Hedging strategies in energy markets: The case of electricity retailers. Energy Econ 51:503-509. https://doi.org/10.1016/j.eneco.2015.06.021

Chang C-H, Lin P, Zhang J, Jeng J-Y (2015) Time dependent adaptive pricing for mobile internet access. In: 2015 IEEE Conference on Computer Communications Workshops (INFOCOM WKSHPS). IEEE, Hong Kong. pp 540-545. https:// doi.org/10.1109/INFCOMW.2015.7179441. http://ieeexplore.ieee.org/document/7179441/

Cook DJ (2012) How smart is your home? Science 335(6076):1579-1581. https://doi.org/10.1126/science.1217640

Dauer D, Karaenke P, Weinhardt C (2015) Load Balancing in the Smart Grid: A Package Auction and Compact Bidding Language. In: Proceedings of the 36th International Conference on Information Systems (ICIS). Association for Information Systems, Fort Worth

D'hulst R, Labeeuw W, Beusen B, Claessens S, Deconinck G, Vanthournout K (2015) Demand response flexibility and flexibility potential of residential smart appliances: Experiences from large pilot test in Belgium. Appl Energy 155:79-90. https://doi.org/10.1016/j.apenergy.2015.05 
Eisel M, Hildebrandt B, Kolbe L, Schmidt J (2015) Applying Demand Response Programs for Electric Vehicle Fleets. In: Proceedings of the 21st Americas Conference on Information Systems (AMCIS). Association for Information Systems, Puerto Rico

Ericson T (2011) Households' self-selection of dynamic electricity tariffs. Appl Energy 88(7):2541-2547. https://doi.org/10. 1016/j.apenergy.2011.01.024

Fridgen G, Häfner L, König C, Sachs T (2014) Toward Real Options Analysis of IS-Enabled Flexibility in Electricity Demand. In: Proceedings of the 35th International Conference on Information Systems (ICIS). Association for Information Systems. http://aisel.aisnet.org/icis2014/proceedings/ConferenceTheme/17

Fridgen, G, Häfner L, König C, Sachs T (2016) Providing utility to utilities: The value of information systems enabled flexibility in electricity consumption. J Assoc Inf Syst 17(8):537-563. https://doi.org/10.17705/1jais.00434

Fridgen G, Kahlen M, Ketter W, Rieger A, Thimmel M (2018) One rate does not fit all: An empirical analysis of electricity tariffs for residential microgrids. Appl Energy 210:800-814. https://doi.org/10.1016/j.apenergy.2017.08.138

Goebel C, Jacobsen H-A, del Razo V, Doblander C, Rivera J, Ilg J, Flath C, Schmeck H, Weinhardt C, Pathmaperuma D, Appelrath H-J, Sonnenschein M, Lehnhoff S, Kramer O, Staake T, Fleisch E, Neumann D, Strüker J, Erek K, Zarnekow R, Ziekow H, Lässig J (2014) Energy informatics. Bus Inf Syst Eng 6(1):25-31. https://doi.org/10.1007/s12599-013-0304-2

Gottwalt S, Ketter W, Block C, Collins J, Weinhardt C (2011) Demand side management-A simulation of household behavior under variable prices. Energy Policy 39(12):8163-8174. https://doi.org/10.1016/j.enpol.2011.10.016

Gupta A, Stahl DO, Whinston AB (1997) The Internet: a future tragedy of the commons? In: Computational Approaches to Economic Problems. Springer, Boston. pp 347-361

Ha S, Sen S, Joe-Wong C, Im Y, Chiang M (2012) TUBE: Time-dependent pricing for mobile data. In: Proceedings of the ACM SIGCOMM 2012 Conference on Applications, Technologies, Architectures, and Protocols for Computer Communication. ACM Press, New York. pp 247-258. https://doi.org/10.1145/2342356.2342402. http://dl.acm.org/ citation.cfm?doid $=2342356.2342402$

Hamilton JD (1994) Time Series Analysis. Princeton University Press, Princeton

Jiang Y, Shahrad M, Wentzlaff D, Tsang DHK, Joe-Wong C (2019) Burstable Instances for Clouds: Performance Modeling, Equilibrium Analysis, and Revenue Maximization. In: IEEE INFOCOM 2019 - IEEE Conference on Computer Communications. IEEE, Paris. pp 1576-1584. https://doi.org/10.1109/INFOCOM.2019.8737634. https://ieeexplore.ieee. org/document/8737634/

Joe-Wong C, Ha S, Chiang M (2011) Time-Dependent Broadband Pricing: Feasibility and Benefits. In: 2011 31st International Conference on Distributed Computing Systems. IEEE, Minneapolis. pp 288-298. https://doi.org/10. 1109/ICDCS.2011.81. http://ieeexplore.ieee.org/document/5961710/

Joe-Wong C, Sen S, Ha S, Chiang M (2012) Optimized day-ahead pricing for smart grids with device-specific scheduling flexibility. IEEE J Sel Areas Commun 30(6):1075-1085. https://doi.org/10.1109/JSAC.2012.120706

Kaufmann J, Kienscherf PA, Ketter W (2020) Modeling and Managing Joint price and Volumetric Risk for Volatile Electricity Portfolios. Energies 13(14):3578. https://doi.org/10.3390/en13143578

Ketter W, Collins J, Gini M, Gupta A, Schrater P (2009) Detecting and forecasting economic regimes in multi-agent automated exchanges. Decis Support Syst 47(4):307-318. https://doi.org/10.1016/j.dss.2009.05.012

Ketter, W, Collins J, Gini M, Gupta A, Schrater P (2012) Real-time tactical and strategic sales management for intelligent agents guided by economic regimes. Inf Syst Res 23(4):1263-1283. https://doi.org/10.1287/isre.1110.0415

Ketter W, Collins J, Reddy P (2013) Power TAC: A competitive economic simulation of the smart grid. Energy Econ 39:262-270. https://doi.org/10.1016/j.eneco.2013.04.015

Ketter W, Collins J, Saar-Tsechansky M, Marom O (2018) Information systems for a smart electricity grid. ACM Trans Manag Inf Syst 9(3):1-22. https://doi.org/10.1145/3230712

Ketter W, Peters M, Collins J, Gupta A (2016) Competitive benchmarking: An IS research approach to address wicked problems with big data and analytics. MIS Quarterly 40(4):1057-1080. https://doi.org/10.25300/MISQ/2016/40.4.12

Ketter, W, Peters M, Collins J, Gupta A (2016) A multiagent competitive gaming platform to address societal challenges. MIS Quarterly 40(2):447-460. https://doi.org/10.25300/MISQ/2016/40.2.09

Kondziella H, Bruckner T (2016) Flexibility requirements of renewable energy based electricity systems - a review of research results and methodologies. Renew Sust Energ Rev 53:10-22. https://doi.org/10.1016/j.rser.2015.07.199

Koolen D, Qiu L, Ketter W, Gupta A (2017) The Sustainability Tipping Point in Electricity Markets. In: Proceedings of the 38th International Conference on Information Systems (ICIS). Association for Information Systems, Seoul

Koroleva K, Kahlen M, Ketter W, Rook L, Lanz F (2014) Tamagocar: Using a simulation app to explore price elasticity of demand for electricity of electric vehicle users. In: Proceedings of the 35th International Conference on Information Systems (ICIS). Association for Information Systems, Auckland

Meier H, Fünfgeld C, Adam T, Schieferdecker B (1999) Repräsentative VDEW-Lastprofile. https://doi.org/10.1 109/CSE.2010.49

Oum Y, Oren S, Deng S (2006) Hedging quantity risks with standard power options in a competitive wholesale electricity market. Nav Res Logist 53(7):697-712. https://doi.org/10.1002/nav.20184

Parag Y, Sovacool BK (2016) Electricity market design for the prosumer era. Nat Energy 1(4):1-6. https://doi.org/10.1038/ nenergy.2016.32

Schmidt J, Busse S (2013) The Value of IS to Ensure the Security of Energy Supply - The Case of Electric Vehicle Charging. In: Proceedings of the 19th Americas Conference on Information Systems (AMCIS). Association for Information Systems, Chicago

Sen S, Joe-Wong C, Ha S, Chiang M (2013) A survey of smart data pricing: Past proposals, current plans, and future trends. ACM Comput Surv 46(2):1-37. https://doi.org/10.1145/2543581.2543582

Sen, S, Joe-Wong C, Ha S, Chiang M (2015) Smart data pricing. Commun ACM 58(12):86-93. https://doi.org/10.1145/2756543

Sen S, Joe-Wong C, Ha S, Chiang M (2019) Time-dependent pricing for multimedia data traffic: analysis, systems, and trials. IEEE J Sel Areas Commun 37(7):1504-1517. https://doi.org/10.1109/JSAC.2019.2916490

Shih JS, Katz RH, Joseph AD (2001) Pricing experiments for a computer-telephony-service usage allocation. In: GLOBECOM'01. IEEE Global Telecommunications Conference (Cat. No.01CH37270). IEEE, San Antonio Vol. 4. pp 2450-2454. https://doi.org/10.1109/GLOCOM.2001.966217. http://ieeexplore.ieee.org/document/966217/

Valogianni K, Ketter W (2016) Effective demand response for smart grids: Evidence from a real-world pilot. Decis Support Syst 91:48-66. https://doi.org/10.1016/j.dss.2016.07.007 
Valogianni K, Ketter W, Collins J, Zhdanov D (2018) Facilitating a Sustainable Electric Vehicle Transition Facilitating a Sustainable Electric Vehicle Transition through Consumer Utility Driven Pricing. In: Proceedings of the 39th International Conference on Information Systems (ICIS). Association for Information Systems, San Francisco

Valogianni K, Ketter W, Collins J, Zhdanov D (2020) Sustainable Electric Vehicle Charging using Adaptive Pricing. Prod Oper Manag 29(6):1550-1572. https://doi.org/10.1111/poms.13179

Watson RT, Boudreau M-C, Chen AJ (2010) Information systems and environmentally sustainable development: energy informatics and new directions for the IS community. MIS Quarterly:23-38

Watson RT, Lawrence TM, Boudreau MC, Johnsen KJ (2013) Design of a demand response system: Economics and information systems alignment. In: Proceedings of the 21st European Conference on Information Systems. Association for Information Systems

Xu H, Li B (2013) Dynamic cloud pricing for revenue maximization. IEEE Trans Cloud Comput 1(2):158-171. https://doi. org/10.1109/TCC.2013.15

Yamamoto Y, Suzuki A, Fuwa Y, Sato T (2008) Decision-making in electrical appliance use in the home. Energy Policy 36(5):1679-1686. https://doi.org/10.1016/j.enpol.2008.01.022

Zhang L, Wu W, Wang D (2014) Time dependent pricing in wireless data networks: Flat-rate vs. usage-based schemes. In: IEEE INFOCOM 2014 - IEEE Conference on Computer Communications. IEEE, Toronto. pp 700-708. https://doi.org/10. 1109/INFOCOM.2014.6847996. http://ieeexplore.ieee.org/document/6847996/

Zheng L, Joe-Wong C, Tan CW, Chiang M, Wang X (2015) How to Bid the Cloud. In: Proceedings of the 2015 ACM Conference on Special Interest Group on Data Communication - SIGCOMM '15. ACM Press, New York Vol. 45. pp 71-84. https://doi.org/10.1145/2785956.2787473. http://dl.acm.org/citation.cfm?doid=2785956.2787473

\section{Publisher's Note}

Springer Nature remains neutral with regard to jurisdictional claims in published maps and institutional affiliations.

\section{Submit your manuscript to a SpringerOpen ${ }^{\circ}$ journal and benefit from:}

- Convenient online submission

- Rigorous peer review

- Open access: articles freely available online

- High visibility within the field

- Retaining the copyright to your article

Submit your next manuscript at $\boldsymbol{\triangleright}$ springeropen.com 